\title{
Long Survival of a Small-Cell Lung Cancer Patient Who Received Maintenance Chemotherapy with Irinotecan
}

\author{
Yoshitaka Yagi $^{a} \quad$ Young Hak Kim $^{a} \quad$ Noriyuki Tajima $^{b} \quad$ Kiichiro Baba $^{\mathrm{b}}$

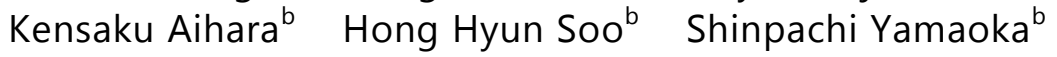 \\ Michiaki Mishima ${ }^{a}$ \\ ${ }^{a}$ Department of Respiratory Medicine, Kyoto University Graduate School of Medicine, \\ Kyoto, and 'Division of Respiratory Medicine, Osakafu Saiseikai Noe Hospital, \\ Osaka, Japan
}

\section{Key Words}

Small-cell lung cancer · Irinotecan · Maintenance $\cdot$ Long survivor $\cdot$ Extensive disease

\begin{abstract}
Lung cancer is the leading cause of cancer-related death worldwide. Small-cell lung cancer (SCLC) accounts for approximately $15 \%$ of all lung cancers. It is characterized by rapid tumor growth and early metastasis to multiple organs. Response to initial chemotherapy is generally good; however, the majority of patients develop recurrence and the prognosis of such patients is reportedly 2-4 months. Evolution of the treatment for SCLC has stagnated, and cisplatin + etoposide has been the standard chemotherapy for decades. Meanwhile, the combination of cisplatin + irinotecan has demonstrated equivalent efficacy to cisplatin + etoposide. Recently, maintenance chemotherapy has been extensively investigated in nonsmall-cell lung cancer (NSCLC), and is currently recommended as a standard treatment in clinical guidelines. On the contrary, a maintenance strategy has not been established for SCLC. Here, we describe an SCLC patient who received maintenance chemotherapy with irinotecan for more than 2 years after induction chemotherapy with cisplatin + irinotecan, and survived long term with no recurrence.


Yagi et al.: Long Survival of a Small-Cell Lung Cancer Patient Who Received Maintenance Chemotherapy with Irinotecan

\section{Introduction}

Lung cancer is the leading cause of cancer-related death worldwide [1]. Small-cell lung cancer (SCLC) accounts for approximately 15\% of all lung cancers [2], and it is characterized by rapid tumor growth and early metastasis to multiple organs. Response to initial chemotherapy is generally good; however, the majority of patients develop recurrence and the prognosis of such patients remains poor [3]. Recently, a strategy of maintenance chemotherapy has been established for non-small-cell lung cancer (NSCLC) and is currently recommended as a standard treatment in clinical guidelines [4, 5]; however, cumulative data have indicated that this maintenance strategy is not effective for SCLC.

\section{Case Report}

A 58-year-old Japanese man was referred to our hospital due to a dry cough continuing for over 3 weeks. He was a former smoker with a 45 pack-year history. Chest X-ray showed left pleural effusion and consolidation in the left hilum. Computed tomography (CT) of the chest revealed left pleural effusion and a large tumor of about $120 \mathrm{~mm}$ invading the aorta and main pulmonary artery directly (fig. 1). He was diagnosed with SCLC based on pleural effusion cytology. The serum concentration of neuron-specific enolase had increased to 24.8 $\mathrm{ng} / \mathrm{ml}$, and pro-gastrin-releasing peptide had also increased to $987.5 \mathrm{pg} / \mathrm{ml}$. Abdominal CT, whole-body bone scintigraphy and brain magnetic resonance imaging did not reveal any distant metastasis. Therefore, the clinical stage of his disease was determined as T4N2M1a, stage IV. Four cycles of chemotherapy, consisting of cisplatin and irinotecan, were performed and a partial response was achieved (fig. 2). Neuron-specific enolase and pro-gastrinreleasing peptide levels decreased to the normal range. Toxicity was quite mild and the patient had a strong wish to continue chemotherapy. Therefore, we started maintenance chemotherapy with irinotecan after the initial treatment. The patient underwent 24 cycles of maintenance treatment with irinotecan without marked toxicity. Subsequently, 2 years and 6 months after the initial diagnosis, ${ }^{18} \mathrm{~F}$-fluorodeoxyglucose positron emission tomography showed no positive sign of disease; the main tumor, lymph nodes, and pleural effusion had completely disappeared and the response was defined as a complete response (fig. 3). Based on these results, we decided to withdraw chemotherapy. Currently ( 3 years since the initial diagnosis), disease relapse has not been documented and the patient is still alive without any complaints.

\section{Discussion}

Recent meta-analyses have shown that thoracic radiotherapy with concurrent chemotherapy resulted in a 5-year survival rate of $20-30 \%$ in patients with limited disease; however, long-term survivors with extensive disease are extremely rare [6]. Consequently, the majority of SCLC patients inevitably develop recurrence. Currently, topotecan is the only drug approved by the US Food and Drug Administration for relapsed SCLC, and is considered the standard second-line chemotherapy in many countries [7]. More recently, amrubicin has also shown promising antitumor activity in this setting $[8,9]$; however, the prognosis of such patients remains dismal. Although maintenance chemotherapy has been extensively investigated for NSCLC and is currently recommended as a standard treatment in clinical guidelines [4, 5], the strategy has not been established for SCLC. However, previous studies 


\begin{tabular}{l|l}
\hline DOI: $10.1159 / 000356826$ & $\begin{array}{l}\text { C } 2013 \text { S. Karger AG, Basel } \\
\text { www.karger.com/cro }\end{array}$ \\
\hline
\end{tabular}

Yagi et al.: Long Survival of a Small-Cell Lung Cancer Patient Who Received Maintenance Chemotherapy with Irinotecan

tested only old agents, and newer agents such as irinotecan and amrubicin have not been investigated in the maintenance setting. Considering that the maintenance strategy succeeded in NSCLC using newer agents, such as pemetrexed and erlotinib, which are more effective and less toxic than older agents, newer agents for SCLC, such as irinotecan, topotecan, and amrubicin, should also be investigated in the maintenance setting for SCLC. To our knowledge, only one study has investigated the efficacy of irinotecan as maintenance chemotherapy in SCLC [10]. Although the results of the study were negative, our successful case indicates that maintenance strategy may merit further investigation for patients with SCLC.

\section{Disclosure Statement}

No author has a financial relationship with a commercial entity that has an interest in the topic of this paper.

\section{References}

1 Jemal A, Bray F, Center MM, Ferlay J, Ward E, Forman D: Global cancer statistics. CA Cancer J Clin 2011;61:69-90.

2 Field JK, Duffy SW: Lung cancer screening: the way forward. Br J Cancer 2008;99:557-562.

3 Lally BE, Urbanic JJ, Blackstock AW, Miller AA, Perry MC: Small cell lung cancer: have we made any progress over the last 25 years? Oncologist 2007;12:1096-1104.

-4 Azzoli CG, Temin S, Aliff T, Baker S Jr, Brahmer J, Johnson DH, Laskin JL, Masters G, Milton D, Nordquist L, Pao W, Pfister DG, Piantadosi S, Schiller JH, Smith R, Smith TJ, Strawn JR, Trent D, Giaccone G, American Society of Clinical Oncology: 2011 Focused Update of 2009 American Society of Clinical Oncology Clinical Practice Guideline Update on Chemotherapy for Stage IV Non-Small-Cell Lung Cancer. J Clin Oncol 2011;29:3825-3831.

5 Peters S, Adjei AA, Gridelli C, Reck M, Kerr K, Felip E, ESMO Guidelines Working Group: Metastatic nonsmall-cell lung cancer (NSCLC): ESMO Clinical Practice Guidelines for diagnosis, treatment and follow-up. Ann Oncol 2012;23(suppl 7):vii56-vii64.

-6 Sørensen M, Pijls-Johannesma M, Felip E, ESMO Guidelines Working Group: Small-cell lung cancer: ESMO Clinical Practice Guidelines for diagnosis, treatment and follow-up. Ann Oncol 2010;21(suppl):v120-v125.

-7 von Pawel J, Schiller JH, Shepherd FA, Fields SZ, Kleisbauer JP, Chrysson NG, Stewart DJ, Clark PI, Palmer MC, Depierre A, Carmichael J, Krebs JB, Ross G, Lane SR, Gralla R: Topotecan versus cyclophosphamide, doxorubicin, and vincristine for the treatment of recurrent small-cell lung cancer. J Clin Oncol 1999;17:658667.

-8 Inoue A, Sugawara S, Yamazaki K, Maemondo M, Suzuki T, Gomi K, Takanashi S, Inoue C, Inage M, Yokouchi H, Watanabe H, Tsukamoto T, Saijo Y, Ishimoto O, Hommura F, Nukiwa T: Randomized phase II trial comparing amrubicin with topotecan in patients with previously treated small-cell lung cancer: North Japan Lung Cancer Study Group Trial 0402. J Clin Oncol 2008;26:5401-5406.

-9 Jotte R, Conkling P, Reynolds C, Galsky MD, Klein L, Fitzgibbons JF, McNally R, Renschler MF, Oliver JW: Randomized phase II trial of single-agent amrubicin or topotecan as second-line treatment in patients with small-cell lung cancer sensitive to first-line platinum-based chemotherapy. J Clin Oncol 2011;29:287-293.

-10 Han JY, Kim HT, Lim KY, Yoon SJ, Lee DH, Lee JS: Randomized phase II study of maintenance irinotecan therapy versus observation following induction chemotherapy with irinotecan and cisplatin in extensive disease small cell lung cancer. J Thorac Oncol 2008;3:1039-1045. 
Yagi et al.: Long Survival of a Small-Cell Lung Cancer Patient Who Received Maintenance Chemotherapy with Irinotecan
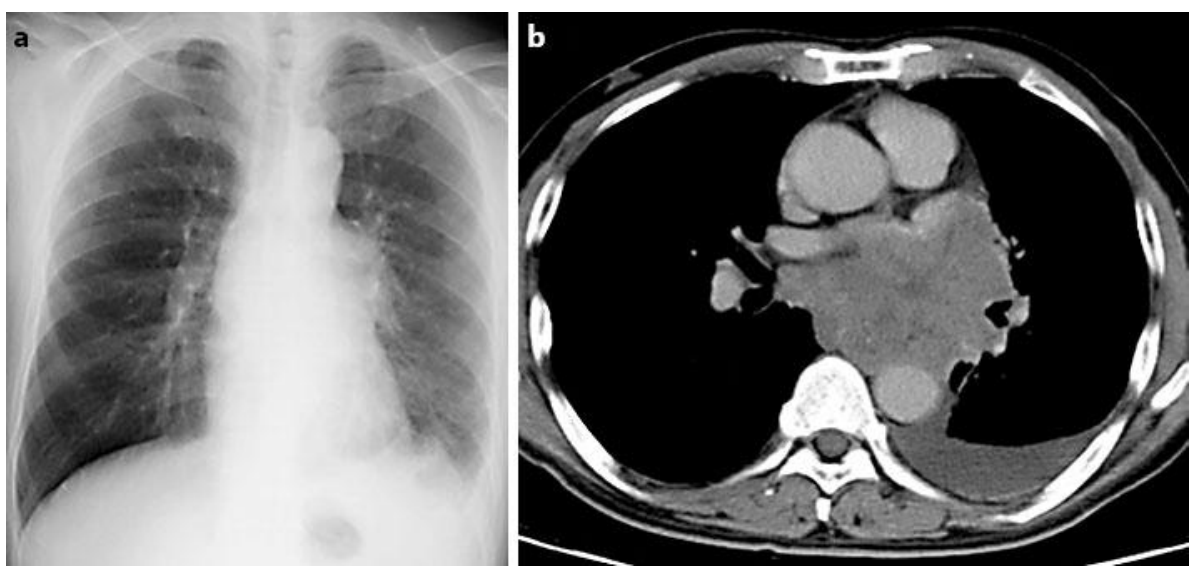

Fig. 1. A large tumor located in the mediastinum with accompanying left pleural effusion is shown. The tumor is about $120 \mathrm{~mm}$ in diameter and invades the main pulmonary artery and aorta. a Chest X-ray. b Enhanced CT.

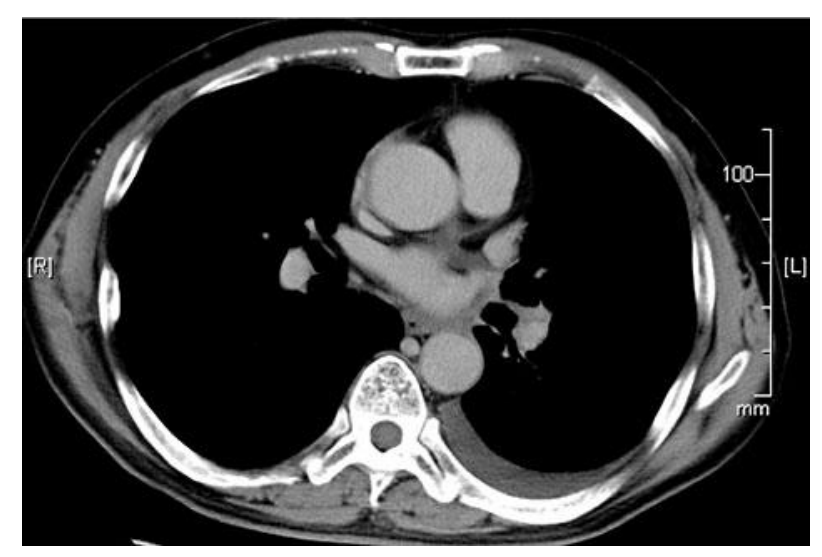

Fig. 2. Enhanced CT showing a markedly reduced tumor and pleural effusion after four cycles of induction chemotherapy. 


\section{Case Reports in Oncology}

\begin{tabular}{l|l}
\hline Case Rep Oncol 2013;6:569-573 & \\
\hline DOI: 10.1159/000356826 & $\begin{array}{l}\text { (c) 2013 S. Karger AG, Basel } \\
\text { www.karger.com/cro }\end{array}$ \\
\hline
\end{tabular}

Yagi et al.: Long Survival of a Small-Cell Lung Cancer Patient Who Received Maintenance Chemotherapy with Irinotecan

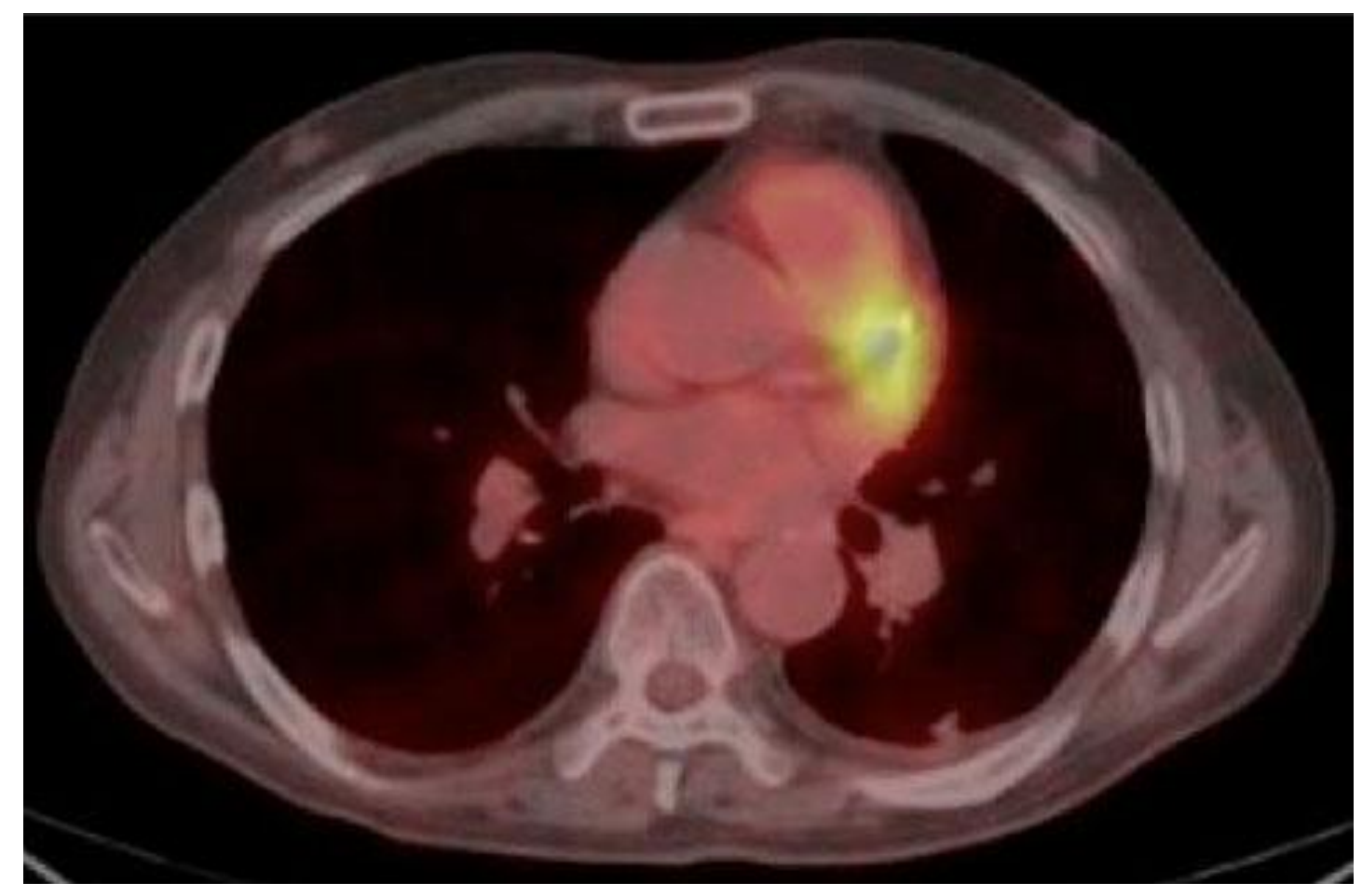

Fig. 3. ${ }^{18 F-f l u o r o d e o x y g l u c o s e ~ p o s i t r o n ~ e m i s s i o n ~ t o m o g r a p h y ~ s h o w i n g ~ c o m p l e t e ~ r e s p o n s e ~ a f t e r ~} 24$ cycles of maintenance chemotherapy with irinotecan. 